University of Nebraska - Lincoln

DigitalCommons@University of Nebraska - Lincoln

\title{
Effects of Landsat 5 Thematic Mapper and Landsat 7 Enhanced Thematic Mapper Plus radiometric and geometric calibrations and corrections on landscape characterization
}

\author{
James E. Vogelmann \\ USGS, vogel@usgs.gov \\ Dennis Helder \\ South Dakota State University, dennis.helder@sdstate.edu \\ Ron Morfitt \\ USGS, rmorfitt@usgs.gov \\ Michael J. Choate \\ USGS, choate@usgs.gov \\ James W. Merchant \\ University of Nebraska-Lincoln, jmerchant1@unl.edu \\ See next page for additional authors \\ Follow this and additional works at: https://digitalcommons.unl.edu/usgsstaffpub \\ Part of the Geology Commons, Oceanography and Atmospheric Sciences and Meteorology Commons, \\ Other Earth Sciences Commons, and the Other Environmental Sciences Commons
}

Vogelmann, James E.; Helder, Dennis; Morfitt, Ron; Choate, Michael J.; Merchant, James W.; and Bulley, Henry, "Effects of Landsat 5 Thematic Mapper and Landsat 7 Enhanced Thematic Mapper Plus radiometric and geometric calibrations and corrections on landscape characterization" (2001). USGS Staff -- Published Research. 527.

https://digitalcommons.unl.edu/usgsstaffpub/527

This Article is brought to you for free and open access by the US Geological Survey at DigitalCommons@University of Nebraska - Lincoln. It has been accepted for inclusion in USGS Staff -- Published Research by an authorized administrator of DigitalCommons@University of Nebraska - Lincoln. 


\section{Authors}

James E. Vogelmann, Dennis Helder, Ron Morfitt, Michael J. Choate, James W. Merchant, and Henry Bulley 


\title{
Effects of Landsat 5 Thematic Mapper and Landsat 7 Enhanced Thematic Mapper Plus radiometric and geometric calibrations and corrections on landscape characterization ${ }^{\text {ts }}$
}

\author{
James E. Vogelmann ${ }^{\mathrm{a}, *}$, Dennis Helder ${ }^{\mathrm{b}}$, Ron Morfitt ${ }^{\mathrm{a}}$, Michael J. Choate ${ }^{\mathrm{a}}$, \\ James W. Merchant ${ }^{\mathrm{c}}$, Henry Bulley ${ }^{\mathrm{c}}$ \\ ${ }^{a}$ Raytheon Corporation, USGS, EROS Data Center, Sioux Falls, SD 57198, USA \\ ${ }^{\mathrm{b}}$ Box 220, Harding Hall, South Dakota State University, Brookings, SD 57007, USA \\ ${ }^{\mathrm{c}} 113$ Nebraska Hall, CALMIT, Conservation and Survey Division, University of Nebraska, Lincoln, NE 68506, USA
}

Received 18 January 2000; received in revised form 8 December 2000; accepted 30 April 2001

\begin{abstract}
The Thematic Mapper (TM) instruments onboard Landsats 4 and 5 provide high-quality imagery appropriate for many different applications, including land cover mapping, landscape ecology, and change detection. Precise calibration was considered to be critical to the success of the Landsat 7 mission and, thus, issues of calibration were given high priority during the development of the Enhanced Thematic Mapper Plus (ETM+). Data sets from the Landsat $5 \mathrm{TM}$ are not routinely corrected for a number of radiometric and geometric artifacts, including memory effect, gain/bias, and interfocal plane misalignment. In the current investigation, the effects of correcting vs. not correcting these factors were investigated for several applications. Gain/bias calibrations were found to have a greater impact on most applications than did memory effect calibrations. Correcting interfocal plane offsets was found to have a moderate effect on applications. On June 2, 1999, Landsats 5 and 7 data were acquired nearly simultaneously over a study site in the Niobrara, NE area. Field radiometer data acquired at that site were used to facilitate crosscalibrations of Landsats 5 and 7 data. Current findings and results from previous investigations indicate that the internal calibrator of Landsat 5 TM tracked instrument gain well until 1988. After this, the internal calibrator diverged from the data derived from vicarious calibrations. Results from this study also indicate very good agreement between prelaunch measurements and vicarious calibration data for all Landsat 7 reflective bands except Band 4 . Values are within about $3.5 \%$ of each other, except for Band 4, which differs by $10 \%$. Coefficient of variation (CV) values derived from selected targets in the imagery were also analyzed. The Niobrara Landsat 7 imagery was found to have lower CV values than Landsat 5 data, implying that lower levels of noise characterize Landsat 7 data than current Landsat 5 data. It was also found that following radiometric normalization, the Normalized Difference Vegetation Index (NDVI) imagery and classification products of Landsats 5 and 7 were very similar. This implies that data from the two sensors can be used to measure and monitor the same landscape phenomena and that Landsats 5 and 7 data can be used interchangeably with proper caution. In addition, it was found that difference imagery produced using Landsat 7 ETM + data are of excellent quality. (C) 2001 Elsevier Science Inc. All rights reserved.
\end{abstract}

\section{Introduction}

Accurate information regarding land use and land cover change is critical to many groups. Remotely sensed data can provide the land cover information important for estimating levels and rates of deforestation, habitat fragmentation,

is Any use of trade, product, or firm names is for descriptive purposes only and does not imply endorsement by the US Government.

* Corresponding author. urbanization, wetland degradation, and many other landscape-level phenomena. Such information can, in turn, be incorporated into many regional to global scale models, including those that are used to develop parameters for carbon fluxes and hydrological cycles. Thus, the data derived from remote sensing can form the foundation for answering important ecological questions with regional to global implications.

The quality of information derived from remotely sensed data is dependent upon many factors, including data quality, analysis techniques and interpretations, and numerous tem- 
poral/phenological considerations. This study will focus on issues of calibration and correction. Radiometric and geometric calibrations and corrections are fundamental operations that are used to remove instrument artifacts and atmospheric path degradation from remotely sensed data.

Although the current study will focus on calibrations and corrections relevant to Landsats 5 and 7 data, it should be noted that some of the artifacts that will be discussed have broad implications for a wide suite of satellite systems. For instance, the atmosphere can have significant effects on the data from a wide array of sensors, and inability to correct for atmospheric effects has been shown to influence classification results and Normalized Difference Vegetation Index (NDVI) values (Kaufman, 1989). Meanwhile, other radiometric and geometric artifacts that will be discussed are especially relevant to Landsat 5 Thematic Mapper (TM) and Landsat 7 Enhanced Thematic Mapper Plus (ETM+) data. It is important to assess the relative impact of the artifacts on the products derived from these data sources. Certainly, radiometric and geometric issues have had adverse effects on the quality of the products from other sensors. For instance, the radiometric and geometric degradations that have occurred during the lifetimes of National Oceanic and Atmospheric Administration Advanced Very High Resolution Radiometer sensors have had significant effects on NDVI products (e.g., Brest \& Rossow, 1992; Gutman, 1999; Privette, Fowler, Wick, Baldwin, \& Emery, 1995; Teillet et al., 1990). Radiometric and geometric degradations could also have pronounced effects on Landsat data, which, in turn, will affect the applications. With most types of remotely sensed data, various levels of radiometric and geometric corrections are possible, and each level leaves residual errors of differing types. Although radiometric and geometric accuracy can be quantified, it is often unclear how these errors affect data applications and models derived from the data.

The purpose of this investigation is to determine the effects of different levels and types of correction upon various applications in Landsats 5 and 7 data. Some of the corrections are particularly germane to Landsat $5 \mathrm{TM}$ data. Many of these have been corrected in Landsat 7 ETM+ data. Others, such as atmospheric effects, are pertinent to both sources of data. As a related issue, the matter of comparability and continuity between Landsat $5 \mathrm{TM}$ and Landsat $7 \mathrm{ETM}+$ is important for many monitoring-related applications. A major objective of the study is to the assess level of comparability between Landsat $5 \mathrm{TM}$ and Landsat 7 ETM+.

\section{Landsat TM calibration - background}

The TM sensors onboard Landsats 4 and 5 were specifically designed for quantitative analysis of the Earth's land surfaces. Both TM instruments benefited from stable solidstate detectors and an internal calibrator (IC). The IC consisted of three lamps that provided eight radiance levels to the detectors in the visible and infrared bands (Bands 1-5 and 7), along with a shutter that allowed direct measurements of detector/channel bias. Calibrations are available at the end of each scan - or roughly 14 times/s. Thus, a wealth of calibration data is available from the instrument even within a single scene.

Landsat 5 TM imagery has consistently exhibited very high standards of radiometric and geometric quality (Barker \& Seiferth, 1996; Helder, Boncyk, \& Morfitt, 1998). However, soon after the launch, it became apparent that the radiometric accuracy of the data returned from the sensor was degraded by the presence of several noise signals that manifested themselves as artifacts in resulting TM image products. Although the impairment from the artifacts is not large, it is, nonetheless, significant. After extensive analysis of TM data, it has been determined that three primary radiometric artifacts exist: memory effect (ME), scan-correlated shift (SCS), and coherent noise (CN) (Helder, Barker, Boncyk, \& Markham, 1996). All three of these artifacts are normally difficult to observe in the data except in fairly homogeneous regions, such as water, snow cover, or desert. Although other secondary artifacts have been identified, their effects are less significant and will not be considered here.

The artifact ME has been known by various names in the past, such as bright target recovery or banding. It produces light and dark bands in resulting imagery. The ME pattern is definitely periodic: The bands are always 16 lines wide (before geometric calibration), one brighter scan followed by a darker scan. It is most obvious in homogeneous regions following a sudden transition in intensity, such as at a cloud/ land boundary. It is not constant within a scan, but dies out with distance from the intensity transition boundary. This artifact can cause significant errors in radiometry, on the order of several DN near transitions (Helder, Boncyk, \& Morfitt, 1997).

SCS is a sudden change in the bias of the detectors that occurs in the time interval between scans. All detectors change at the same time, but with different amplitudes. The amount of change is typically quite small, on the order of $1 \mathrm{DN}$ or less. Since all detectors change simultaneously, the effect can be seen in the data as bands (multiples of 16 lines wide) that are of slightly different intensity. The light and dark bands occur randomly, across multiple scans, without significant evidence of periodic structure (Helder et al., 1996).

$\mathrm{CN}$ is normally the least offensive of the three radiometric artifacts, introducing uncertainties on the order of $0.25 \mathrm{DN}$ or less. It is caused by various electronic systems, such as switching power supplies. The exact frequency, phase, and magnitude of $\mathrm{CN}$ is known to vary slightly over short time intervals (Helder, 1999).

Landsat 4 provided imagery from 1982 through most of 1993. Landsat 5, from its launch in 1984, has delivered imagery through the rest of the 20th century and, at the time of this writing, shows no sign of failing in the near future. 
Both instruments were calibrated prior to launch using wellcalibrated laboratory equipment (Barker, 1983). Following its launch, both instruments have been calibrated vicariously through ground-based methods. However, these have been somewhat sporadic and irregular. The IC provides the best source of information for the day-to-day health and calibration of the instruments. The history of the IC calibration has been tracked at several time scales (Helder, 1996). Many interesting events have occurred in regard to the systems. These will be briefly summarized here in the framework of Landsat 5 and their relationship to application accuracy.

Instrument bias has been monitored during the life of the instrument and has maintained a high degree of stability (Helder et al., 1998). Detector bias has exhibited no longterm trends but does show an annual oscillation of about 1 $\mathrm{DN}$ in the warm focal plane. Instrument gain, as determined from the IC, is shown as the solid curves in Fig. 1. Apparent changes in gain may be due to loss of stability of the IC lamps. Since changes in calibration lamps cannot be differentiated from changes in detector gain, vicarious calibrations are needed to resolve this ambiguity. These are also shown in Fig. 1 and discussed further in later sections of this paper.

In addition to being affected by instrument-related radiometric artifacts, geometric accuracy returned from the Landsat $5 \mathrm{TM}$ can be adversely affected by interfocal plane offsets. This means that Bands 1-4, which are on the warm focal plane, may be misaligned with Bands 5 and 7, which are on the cold focal plane. The differences may be on the order of several tenths of a pixel offset. The magnitudes of these offsets were not routinely monitored nor were they characterized during the Landsat 5 mission. Conversely, the interfocal plane offsets will be monitored throughout the Landsat 7 mission. It is also anticipated that the level of geometric accuracy of the Landsat 7 systematic products will be much higher than for Landsat $5 \mathrm{TM}$. This will also be monitored throughout the Landsat 7 mission.

Atmospheric effects will similarly adversely affect both Landsats 5 and 7 data. Within this study, atmospheric effects were modeled for the Landsat 5 TM data for several scenes using the radiative transfer code MODTRAN (Berk, Bernstein, \& Robertson, 1989). One of the goals of this part of the study was to compare the relative changes of atmospheric effects with other radiometric artifacts.

\section{Brookings, SD calibration/application activities summary}

\subsection{Effect of calibrations and corrections on single-scene classifications}

Much initial Landsat TM calibration and applications work has been conducted using a study site in the Brook-
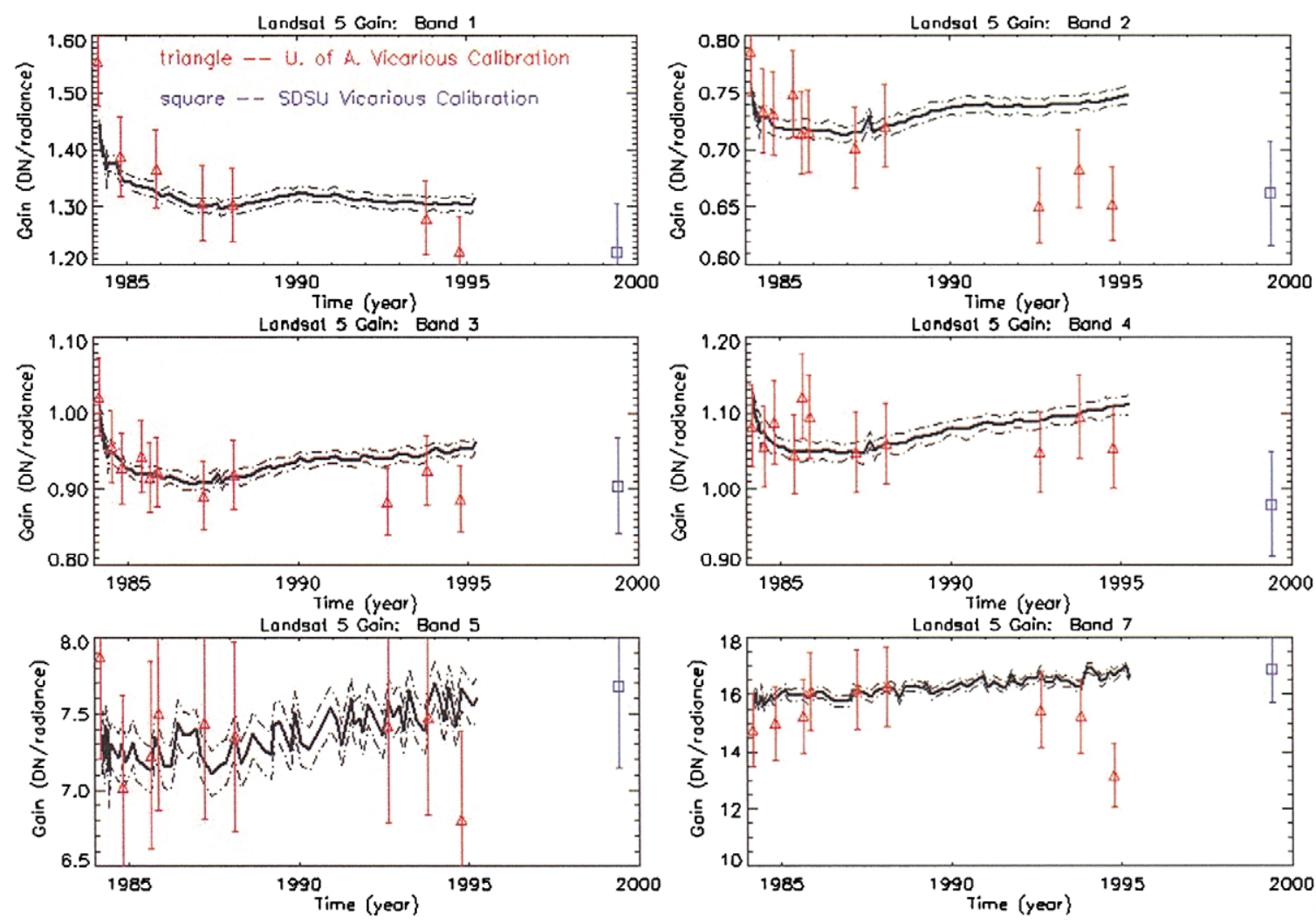

Fig. 1. Comparison between internal calibrator and vicarious calibration estimates. Radiance is in $\mathrm{W} \cdot \mathrm{m}^{-2} \cdot \mathrm{sr}^{-1} \cdot \mu \mathrm{m}^{-1}$. Dashed lines are $\pm 1 \mathrm{~S} . \mathrm{D}$. 
ings, SD (WRS path/row 29/29) area. Many of the results from these investigations have been reported elsewhere (Vogelmann, Choate, Helder, Merchant, \& Bulley, 1999; Vogelmann, Helder, Morfitt, Choate, \& Merchant, 1998), and only the most significant findings will be summarized here. Brookings is located in an intensely agricultural region in eastern South Dakota. During times of Landsat 5 overpasses, Reagan Sun Photometer and Shadowband Radiometer (Yankee Environmental Systems, Turners Falls, MA) data were acquired onsite to enable correction of atmospheric effects in the TM data. The sun photometer points directly at the sun and measures the radiance reaching the ground. It can be used to extract top-of-theatmosphere radiance values through Langley analysis. The shadowband units measure total downwelling irradiance and diffuse downwelling irradiance. This allows estimation of the amount of scattering that occurs in the atmosphere. Data from both instruments are used to calibrate a MODTRAN-based radiative transfer code model of the atmosphere. Two excellent quality Landsat 5 scenes were acquired, processed, and analyzed for this site. These were acquired on July 16, 1997 and July 19, 1998.

Raw Landsat 5 imagery was calibrated for ME and gain/ bias, including SCS (Helder et al., 1997). Atmospheric effects were then removed using established procedures (Berk et al., 1989). After interfocal plane misregistrations were removed (Vogelmann et al., 1998), images were precision terrain-corrected to generate well-calibrated data sets (one for each date of acquisition). Known quantities and types of radiometric and geometric artifacts (including different atmospheric conditions) were then added back to the well-calibrated data set to create new data sets for comparison (Table 1).

A series of supervised classifications was run for each data set (Table 1). A total of 28 training sites were used. These were selected to represent mostly spectrally homogeneous types of land cover (e.g., water, corn, soybeans, pasture, etc.) that characterize the region. For each classification run, the same polygons were used to delineate the pixels from which the statistics were to be drawn. Thus, the differences in classifications resulted solely from differences in the statistical properties of the pixels used, which related solely to the differences in corrections applied. Similarities (or differences) in classification results were summarized by summing up the number of pixels that had the same class values as the classification derived from the well-calibrated data set and were expressed as a percentage (Table 1). No attempt was made to validate classification results. The purpose of this experiment was to determine which artifacts had the greatest impact upon classification results. Thus, percentage similarity values are best viewed as numbers providing for relative comparison among treatments, and the entire procedure may be considered as a sensitivity analysis.

Results from this part of the study indicate that gain/bias (including SCS) had the highest level of impact upon
Table 1

Summary of radiometric and geometric perturbations applied to the July 16 , 1997 Brookings scene and degree of classification similarity

\begin{tabular}{llc}
\hline Data set & Perturbation & $\begin{array}{l}\text { Percent of } \\
\text { similarity (\%) }\end{array}$ \\
\hline 1 & Well-calibrated & 100 \\
2 & Low gain/bias & 83 \\
3 & Nominal gain/bias & 76 \\
4 & High gain/bias & 64 \\
5 & Low memory effect & 94 \\
6 & Nominal memory effect & 92 \\
7 & High memory effect & 88 \\
8 & Clear atmosphere & 84 \\
9 & Typical atmosphere & 83 \\
10 & Hazy atmosphere & 83 \\
11 & IFP moved 0.05 pixel; across & 93 \\
12 & IFP moved 0.10 pixel; across & 89 \\
13 & IFP moved 0.10 pixel; along & 89 \\
14 & IFP moved 0.20 pixel; across & 83 \\
15 & IFP moved 0.30 pixel; across & 77 \\
16 & IFP moved 0.10 pixel; & 86 \\
& along and across direction & \\
\hline
\end{tabular}

"Nominal" implies that actual levels related to a given artifact were simulated and added back to the well-calibrated data.

IFP = interfocal plane.

The percent of similarity is defined as the percentage of pixels that have the same class value (following supervised classification) between the wellcalibrated data set and the data set with added artifacts.

classification results. ME had a relatively small impact upon classification results, whereas atmosphere had moderate impact. Changing interfocal plane alignments (from 0.05 to 0.3 pixel) also appeared to have a moderate impact upon classification results. This impact tended to increase as the interfocal plane distances were increased.

Most of the results presented in Table 1 make sense. Gain/bias is detector-specific, and, in practice, the corrections applied will result in relative increases in DN values for some pixels and relative decreases in DN values for others. Thus, correcting gain/bias will affect all pixels to one degree or another and will affect their statistical properties differentially. Meanwhile, ME tends to affect only those pixels that are in transitional areas between regions of dark and bright reflectance. In addition, ME will affect only the DN values for those bands located on the warm focal plane (Helder et al., 1998). Thus, for an overall classification, ME will most likely affect fewer numbers of pixels than gain/bias, and will only affect the statistical properties of Bands 1-4. Atmospheric corrections as applied in this study essentially affect all pixels but, unlike gain/bias, will affect all pixels consistently for a given correction (i.e., the transformation is essentially linear with constant gains and biases applied). Although the atmospheric corrections will alter the statistical properties of the imagery, the relative relationship among brightness features will be retained. Lastly, correcting interfocal plane offsets can affect all pixels. However, because intrafocal plane offsets in TM imagery are negligible, this type of correction will only affect the 
DN values of the bands located on one of the two focal planes. Thus, interfocal band changes will alter the statistical properties of some but not all of the bands, resulting in a moderate impact on classification results.

It should be stated upfront that the methods used in this analysis were scene dependent. This is especially true for atmospheric corrections, which were specific to summer northern latitude conditions. Such scene-dependent variables could result in different statistical interactions among pixels used in the classifications, which, in turn, could affect classification results. Without conducting similar investigations in other regions, such as tropical areas where atmospheric properties are very different, it is not possible to state with certainty the degree to which results from the current study will be directly applicable to other regions. Despite this concern, the likelihood of significant regional differences is reasonably small, and it is expected that the results obtained from this analysis will be relevant to other regions, at least in the broad sense.

\subsection{Effects of calibrations and corrections on landscape metrics}

Landscapes comprise of a mosaic of land cover patches that differ in size, shape, and composition (Forman \& Godron, 1986). Many landscape metrics have been developed to characterize landscape structure and spatial pattern (e.g., Frohn, 1998; McGarigal \& Marks, 1993; Pan, Domon, de Blois, \& Bouchard, 1999). These metrics facilitate quantification of landscape texture, patch size and shape, land cover interspersion and connectivity, and other spatial dimensions. Landscape metrics provide a quantitative means to explore relationships between landscape patterns and ecological processes.
In this work, the implications of the "improved" radiometric and geometric calibrations on landscape metrics derived from Landsat $5 \mathrm{TM}$ data were assessed. The specific hypothesis of this analysis is that different levels and types of radiometric and geometric calibrations of Landsat 5 TM data will have variable impacts on the landscape metrics derived from the images. The objective here was to assess the impacts of different levels and types of radiometric and geometric calibrations of Landsat $5 \mathrm{TM}$ data on the final landscape metrics derived from the images. The implicit assumption is that any impact on the landscape metrics will ultimately affect metric-based land use and land cover analysis.

The image analyses and landscape metrics calculations were carried out using FRAGSTATS software (McGarigal \& Marks, 1993). All in all, 16 images corresponding to different types and levels of corrections were used in the study. The images corresponded to a $130-\mathrm{km}^{2}$ area of the July Brookings, SD scene used for the classification work described earlier. A supervised classification was performed on all images as described previously. The 28 initial classes were reassigned to nine land use/land cover classes. Landscape metrics were then computed for the classified images (Table 2).

Landscape metrics used in this study are largest patch index (LPI, measuring dominance), contagion (CONTAG), and landscape shape index (LSI, measuring fractal dimension from perimeter/area). The LPI is the percentage of the largest patch in the landscape to the total landscape area. It ranges from $0 \%$ to $100 \%$, where the entire landscape is a single patch. The LSI is a measure of the irregularity of the shape of the landscape. It is equal to 1 for a landscape made up of a single patch and increases without limit as the landscape shape becomes more irregular. CONTAG is a percentage measure of the uniformity of the distributions of adjacencies among unique patch types. It ranges from $0 \%$

Table 2

Landscape metrics derived from supervised classification of Landsat 5 scene of Brookings test site

\begin{tabular}{|c|c|c|c|c|}
\hline Data set & Perturbation & LPI & LSI & CONTAG \\
\hline 1 & Calibrated & 1.77 & 290.36 & 33.42 \\
\hline 2 & Low gain/bias & 4.58 & 278.11 & 36.47 \\
\hline 3 & Nominal gain/bias & 5.74 & 269.10 & 37.96 \\
\hline 4 & High gain/bias & 2.14 & 302.85 & 33.54 \\
\hline 5 & Low memory effect & 3.89 & 285.55 & 34.78 \\
\hline 6 & Nominal memory effect & 3.91 & 284.05 & 34.98 \\
\hline 7 & High memory effect & 3.96 & 289.16 & 34.01 \\
\hline 8 & Clear atmosphere & 3.54 & 289.03 & 35.10 \\
\hline 9 & Typical atmosphere & 5.42 & 282.89 & 35.73 \\
\hline 10 & Hazy atmosphere & 4.43 & 288.13 & 36.22 \\
\hline 11 & IFP moved 0.05 pixel; across & 1.80 & 287.19 & 33.76 \\
\hline 12 & IFP moved 0.10 pixel; across & 1.99 & 285.87 & 33.80 \\
\hline 13 & IFP moved 0.10 pixel; along & 1.49 & 290.92 & 33.36 \\
\hline 14 & IFP moved 0.20 pixel; across & 2.68 & 291.10 & 33.21 \\
\hline 15 & IFP moved 0.30 pixel; across & 2.08 & 288.24 & 33.66 \\
\hline 16 & IFP moved 0.10 pixel; along and across direction & 4.75 & 284.62 & 34.11 \\
\hline
\end{tabular}

LPI= largest patch index; LSI= landscape shape index; CONTAG = contagion. 
for unevenly distributed adjacencies to $100 \%$ for uniformly adjacent patch types within a landscape. Comprehensive reviews of the landscape metrics are presented by McGarigal and Marks (1993) and Riitters et al. (1995).

The landscape metrics derived from images with different levels and types of radiometric and geometric corrections applied were compared with those derived from the well-calibrated image. The results indicate that errors due to gain/bias had more impact on the landscape metrics than the other perturbations tested, although differences were rather slight in most cases. This was especially true for LSI and CONTAG metrics. The correction of interfocal plane misalignment, on the average, had less impact on the landscape metrics than ME or atmospheric perturbations. Although these findings are in general agreement with the results from the classification work described earlier, it should be noted that differences do exist. While the landscape metrics (Table 2) relate to patterns of groups of similar pixels, the classification percentage similarity values (Table 1) relate to pixel-by-pixel differences. Thus, different landscape properties are measured by the two approaches.

\subsection{Effects of calibrations and corrections on difference imagery}

Well-calibrated images were generated for both the July 16, 1997 and July 19, 1998 Brookings scenes. Evaluation of the imagery indicated that despite being acquired during the middle of summer near anniversary dates, the images were surprisingly very different in appearance. Patterns of vegetation greenness were not similar, especially for the croplands that dominate the scenes. These differences ostensibly resulted from different precipitation and temperature regimes, which caused a delay in green-up patterns during the summer of 1997.

A series of difference image data sets was produced for each TM band between the two dates. The well-calibrated difference image for Band 1 (Fig. 2; right) is noise-free. Dark and bright areas represent land cover features that were spectrally different between the two dates. The approximate digital range of values in these images is from -50 (dark; TM Band 1 drop between 1997 and 1998) to +20 (bright; TM band increase between 1997 and 1998). The large, medium bright feature located toward the left part of the image represents a lake. The bright part of this lake represents no change. The subtle wavelike patterns in the lake in the corrected image represent artifacts attributable to $\mathrm{CN}$. This artifact is relatively subtle compared with other radiometric artifacts. No attempts were made to remove this type of noise from the imagery. A Band 1 difference image with nominal gain/bias (Fig. 2; left) shows much striping. Although similar striping patterns attributable to gain/bias (including SCS) were observed in all bands, the pattern was the most obvious in Band 1. Striping is diagonal because the satellite track is inclined with respect to the north-south direction and because of georegistration of the imagery.

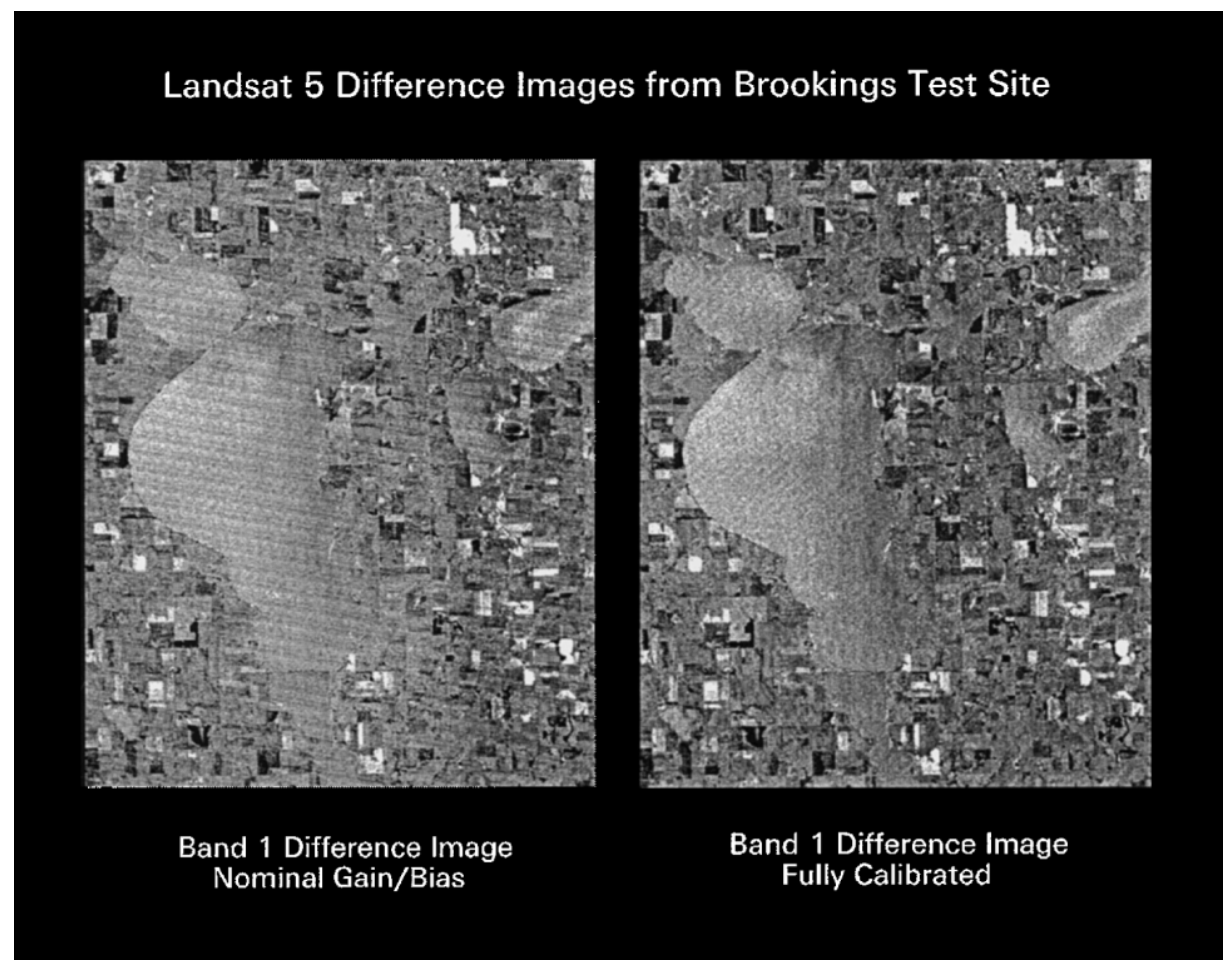

Fig. 2. Comparison between Landsat 5 TM Band 1 difference images with different levels of calibrations and corrections applied. Bright areas in the lakes represent the point of no change. Most values are between - 50 (dark; Band 1 drop between 1997 and 1998 images) and +20 digital numbers (DN) (bright; Band 1 gain between 1997 and 1998). 
An analysis of the levels of error attributable to the different artifacts was to provide comparative estimates of how much noise each artifact contributes on a band-by-band basis. "Noise" images were derived by subtracting noncorrected difference images (i.e., images with known artifacts added back) from the well-calibrated difference image. The statistics from these "noise" images were then evaluated. "Noise" images with mean values of 0 and standard deviations of 0 imply no observable impact caused by the artifact. However, as standard deviations increase, higher levels of impact by the artifact are assumed. The units were kept as DN values to facilitate direct comparison among intraband artifacts (Table 3) and to keep units consistent with those supplied to the user community.

Results from this analysis indicate that gain/bias has a greater impact upon difference imagery than does ME. Values are consistently higher on a band-by-band basis for gain/bias than for ME, with the differences attributable to gain/bias being most apparent in Band 1. It is notable that prelaunch analyses of Landsat 5 bands (NASA, 1985) indicate that Band 1 had appreciably higher levels of noise than Band 2, 3, or 4. This may help to explain some of the noise observable for Band 1 difference data (Fig. 2, Table 3). It should also be noted that Bands 5 and 7 had relatively high levels of noise in the prelaunch analyses.

ME is largest for Band 4 and is minimal for Bands 5 and 7. As noted earlier, ME affects the electronics of the warm but not the cold focal plane and, thus, ME was not expected to have much impact on Bands 5 and 7. That ME affects Band 4 more than Bands $1-3$ is logical, because ME affects DN values near dark-bright transitions, and there are many of these in Band 4 spectral space (e.g., watervegetation boundaries; vegetated-bare soil) as compared to Bands 1-3. The combination of gain/bias and ME is usually only slightly higher than just gain/bias by itself, implying that ME is a relatively minor component of the imagery used in this study. The one exception to this is Band 4, where the combination of gain/bias and ME probably warrants additional attention.

Errors attributable to focal plane misalignment are similar to those of gain/bias for Bands 1-3 but are quite high for Band 4. It should be noted that most of the geometric errors are located along spectral edges, such as in transitions between dark water bodies and adjacent brighter land features. Thus, this type of error is somewhat different from the radiometric instrument artifacts and may not be exactly comparable. No values were reported for Bands 5 and 7 because these bands, located on the cold focal plane, were chosen as the "standard," with the warm focal plane bands (1-4) being aligned (or misaligned) to them. It has been found in previous work that adjustment of band alignment within a focal plane is not necessary.

Potential errors contributed by the atmosphere can be higher than for any of the other artifacts for Bands 1-3. These values were derived through MODTRAN simulations using standard north temperate latitude values. The conclusion that can be drawn from this is that any difference image produced for these bands without any attempts to normalize or remove the atmosphere may result in errors that are relatively large when compared with the instrument-related errors. The potential atmospheric errors diminish from Bands 4 through 7, with little impact noted for either Band 5 or 7 . This is consistent with known effects of the atmosphere (Kaufman, 1989). In general, shorter wavelengths are dominated by molecular aerosol scattering, and the longer wavelengths are dominated by water absorption features. The longer wavelength bands of Landsat are located in spectral regions that avoid the major regions of water absorption and, thus, the effects of the atmosphere on Bands 4, 5, and 7 are minimal when compared with bands 1,2 , and 3 .

The error attributable to atmosphere is likely to be more constant across the scene than for the instrument artifacts. Thus, while absolute values of change may be reasonably large in nonatmospherically corrected (or nonnormalized) data sets, the relative patterns of dark and bright difference DN values and, thus, landscape change patterns across the scene may be mostly valid. Depending upon the application of the difference imagery, the impact of not taking into account atmospheric effects may be large (e.g., obtaining quantitative estimates of biophysical change) or small (e.g., classification of areas converted from vegetation to nonvegetation). Certainly, visible band $\mathrm{DN}$ value

Table 3

Error in difference images attributable to different artifacts

\begin{tabular}{|c|c|c|c|c|c|}
\hline TM band & $\begin{array}{l}\text { Error } \\
\text { (nominal GB) }\end{array}$ & $\begin{array}{l}\text { Error } \\
\text { (nominal ME) }\end{array}$ & $\begin{array}{l}\text { Error (nominal } \\
\mathrm{ME} \text { and } \mathrm{GB} \text { ) }\end{array}$ & $\begin{array}{l}\text { Error (nominal focal } \\
\text { plane offset) }\end{array}$ & $\begin{array}{l}\text { Error (hazy-clear } \\
\text { conditions) }\end{array}$ \\
\hline 1 & 1.52 (4.6) & $0.43(1.3)$ & $1.63(4.9)$ & $1.50(4.5)$ & 10.4 \\
\hline 2 & $0.68(2.1)$ & $0.46(1.4)$ & $0.93(2.8)$ & $0.90(2.7)$ & 7.8 \\
\hline 3 & $0.83(2.5)$ & $0.50(1.5)$ & $1.06(3.2)$ & $1.23(3.7)$ & 10.7 \\
\hline 4 & 1.09 (3.3) & $0.97(2.9)$ & $1.52(4.6)$ & $3.79(11.4)$ & 4.6 \\
\hline 5 & $1.12(3.4)$ & $0.09(0.3)$ & $1.12(3.4)$ & - & 1.3 \\
\hline 7 & $0.73(2.2)$ & $0.06(0.2)$ & $0.74(2.2)$ & - & 0.0 \\
\hline
\end{tabular}

GB refers to gain/bias; ME refers to memory effect.

Values are reported as DN values.

Values in parentheses are $99 \%$ confidence estimates. Assuming that the artifact is not removed, DN changes need to be higher than the values in parentheses to be extremely confident that the individual pixel value has actually changed.

$\mathrm{GB}=$ Gain/Bias; $\mathrm{ME}=$ Memory Effect. 
differences among vegetation communities representing different conditions can be quite subtle, and the changes in several DN values for these communities may be significant from the standpoint of chlorophyll content and overall ecosystem health. Errors due to not correcting the atmosphere (i.e., greater than $7 \mathrm{DN}$; Table 3) are most likely to be well above the threshold of noise tolerance for these types of applications.

It should be noted that the seemingly anomalous value of 7.8 DN for Band 2 compared with other visible band values (10.4 and 10.7 DN for Bands 1 and 3, respectively) is actually quite reasonable. All values in Table 3 are in band-specific DN "units," and when converted to units of radiance, Band 2 value is consistent with other band values. However, it should also be noted that conversion of the $\mathrm{DN}$ values to radiance resulted in the Band 1 value being lower than expected, implying that the MODTRAN simulation underestimated the effect of atmosphere on this band. The important conclusion to be drawn from this work is that the impact of not correcting the atmosphere can be greater than that of not correcting the instrument artifacts for the visible bands.

\section{Niobrara field campaign}

A site in the Niobrara, NE area was selected for crosscalibrating Landsats 5 and $7 \mathrm{TM} / \mathrm{ETM}+$ data. The Nature Conservancy preserve located in this region has been the

\section{U-L ARROW LOCATION: $\mathbf{4 2}^{\circ} \mathbf{4} 7^{\prime} 58.45^{\prime \prime}$ $100^{\circ} 01^{\prime} 13.48^{\prime \prime}$}

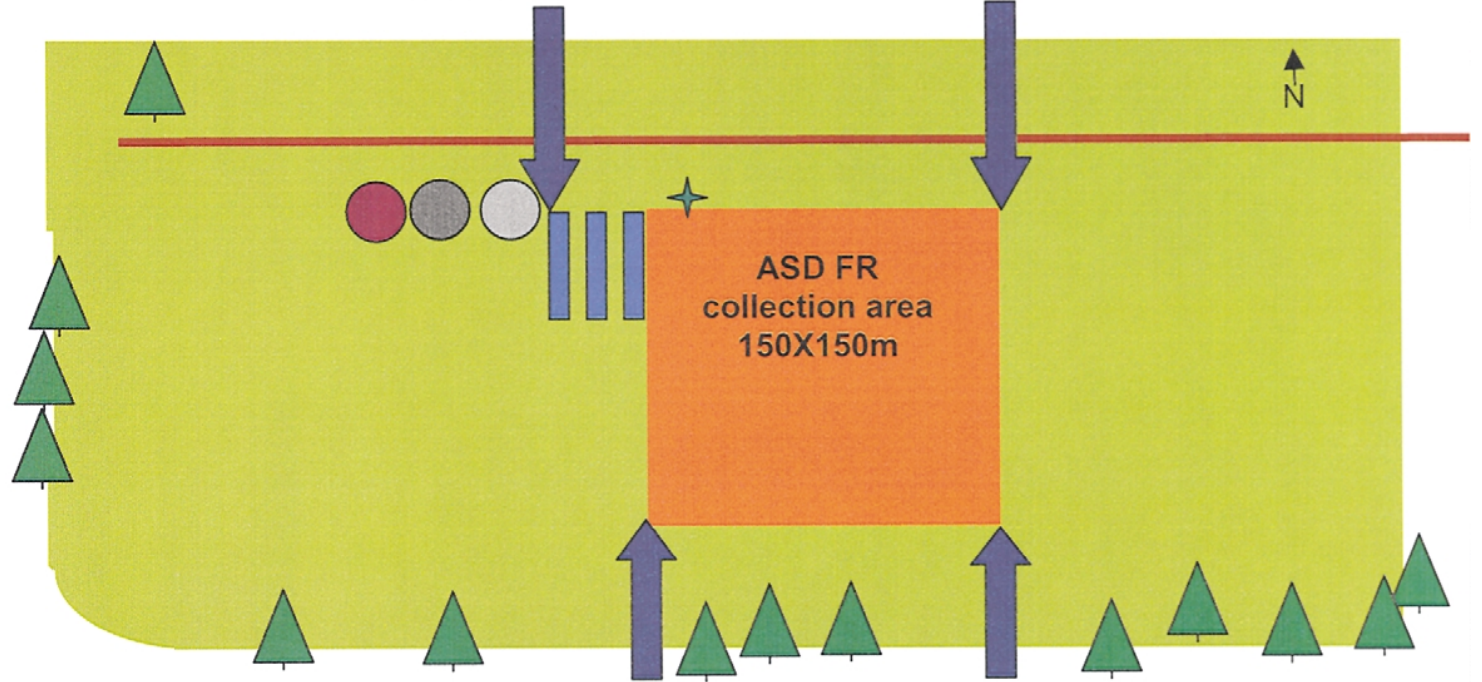

$42^{\circ} 47^{\prime} 52.38^{\prime \prime}$

L-L ARROW LOCATION: N 42 ${ }^{\circ} 47$ '53.89"

W $100^{\circ} 01^{\prime} 14.59 "$
L-R ARROW LOCATION: N

W $100^{\circ} 01 ' 10.05^{\prime \prime}$

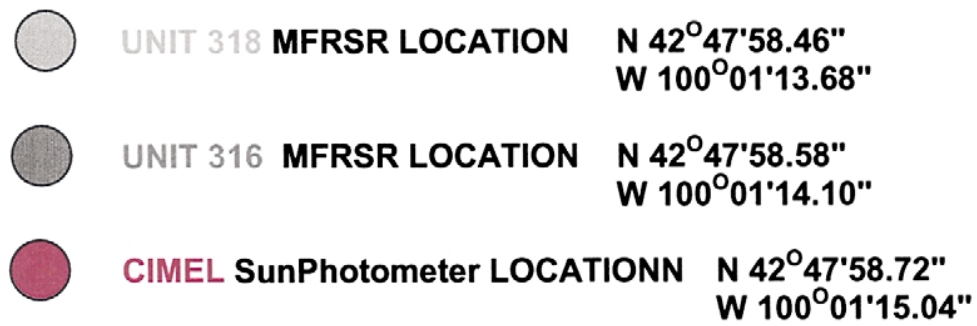

ASD FR DATA COLLECTION AREA

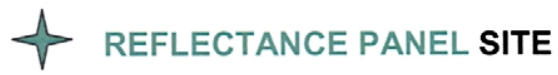

TARP LOCATIONS

\section{Site Elevation 2493 feet}

Fig. 3. Niobrara, NE field site detail. 
site of ongoing related research activities (both field and remote sensing). More pertinent to the current investigation, however, is that on June 2, 1999, Landsat 7 ETM+ and Landsat $5 \mathrm{TM}$ data sets were acquired nearly simultaneously (12:02 and 12:17 central daylight time for Landsats 7 and 5, respectively). The Landsat 7 ETM+ data were acquired for this site prior to Landsat 7's reaching final orbit. Thus, both TM and ETM+ instruments were imaging essentially identical targets through the same atmosphere, enabling an opportunity for crosscalibrating Landsats 5 and 7 data with minimal influence from non-instrument-related artifacts and conditions. Comparison between these two data sets affords the opportunity to ascertain the similarities and dissimilarities between Landsat $5 \mathrm{TM}$ and Landsat $7 \mathrm{ETM}+$, providing information relating to issues of Landsat data continuity. In addition, Landsat $7 \mathrm{ETM}+$ data sets acquired on July 12 and July 28, 1999 were obtained and analyzed. These latter data sets were used to evaluate Landsat 7 image quality of derivative products (difference images/classifications).

The Niobrara, NE site consists of large meadows populated by native prairie grasses. A field campaign was conducted at this site during Landsats 5 and 7 overpasses, with instrumentation deployed on June 1 to be in place for the June 2 overpasses. A detail of the site is shown in Fig. 3. Several radiometers were used, including Multifilter Rotating Shadowband Radiometers (MFRSRs; Yankee Environmental Systems) and a Cimel Sunphotometer (Cimel Electronique, Paris, France). The Cimel is a radiometer that is pointable. Thus, at any desired time, radiance measurements can be made at several wavelengths with the instrument pointed in any direction. A reasonably uniform $150 \times 150-\mathrm{m}$ area dominated by grasses was staked out as

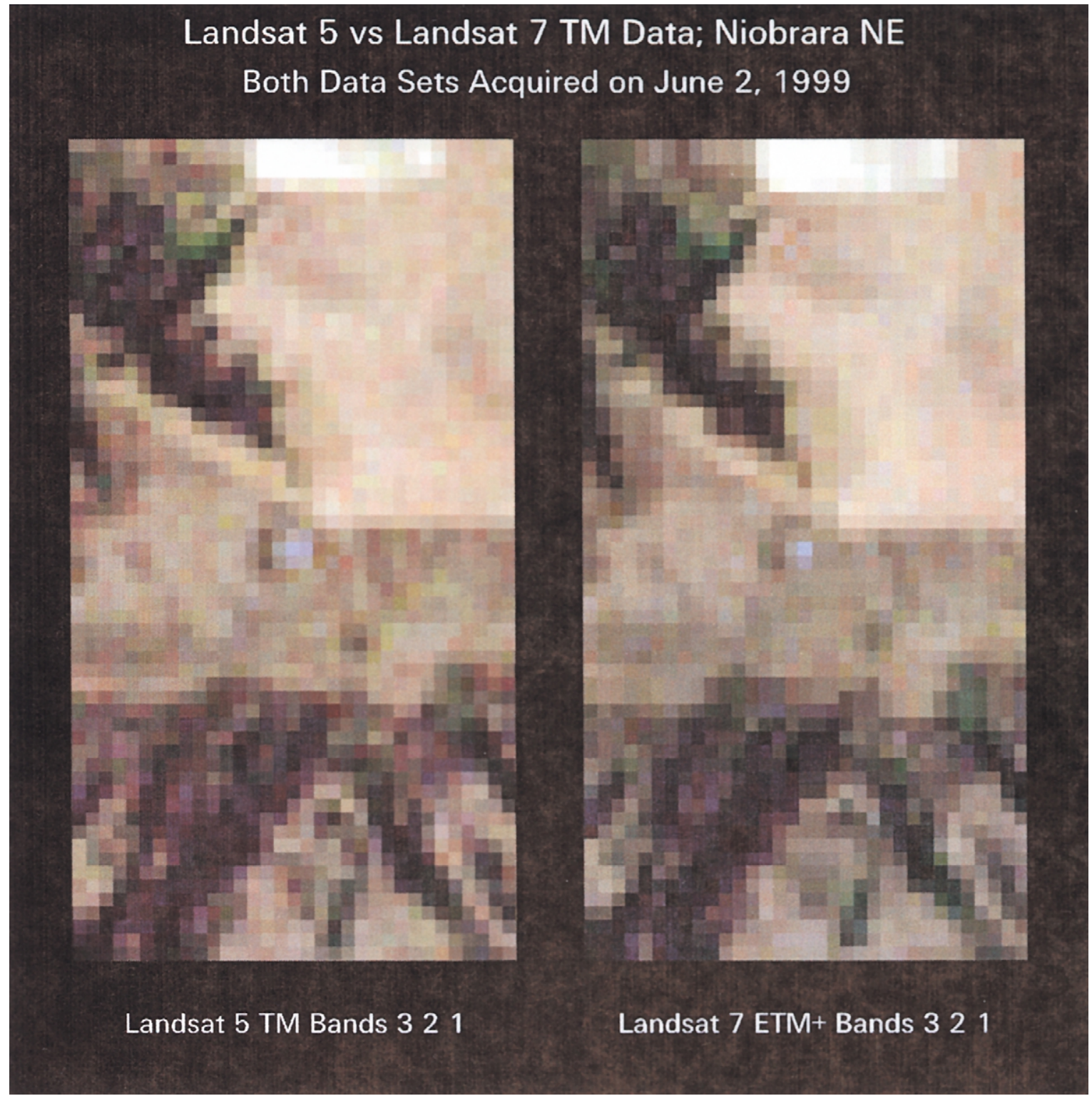

Fig. 4. Landsats 5 and 7 Bands 3, 2, and 1 composites showing location of blue tarp (turquoise pixels) used for calibration work. 
a site for obtaining surface radiances and reflectance using an Analytical Spectral Devices FieldSpec FR (ASD-FR, Analytical Spectral Devices, Boulder, CO) spectroradiometer. To locate the site accurately in the Landsat imagery, we deployed a set of three tarps with a unique spectral signature. Measuring $3 \times 30 \mathrm{~m}$ in size, they were arranged with approximately $3-\mathrm{m}$ spacing between them. These tarps were easily identified in the TM imagery (Fig. 4).

The MFRSRs were set up on June 1, the day before the overpass. They recorded total and diffuse downwelling irradiance for the entire morning of June 2 until about an hour after the overpass occurred. These units were factory calibrated in the fall-winter of 1998. They were also used throughout the summer of 1999. As a result, multiple Langley analyses were available for instrument calibrations. Results from these data indicated instrument accuracy was on the order of $4 \%$ ( 1 S.D.). The measurements were also corrected for cosine and zenith angles and adjusted for the sun/earth distance on that date. Data were collected at 15-s intervals and five channels were used for subsequent modeling: $415,500,615,673$, and $870 \mathrm{~nm}$.

Several parameters were derived from the MFRSR data for subsequent radiative transfer code modeling. Transmittance was calculated for each of the five channels as simply the ratio between the direct normal component and the top of the atmosphere irradiance as determined by the Langley analyses. Diffuse-to-global irradiance ratios were also determined from the MFRSR measurements at all five wave- lengths. Aerosol extinction was derived from the transmittance calculations by first estimating Rayleigh extinction using the following relationship

$\beta_{\mathrm{R}}=0.008735 \lambda^{-4.08} \frac{P}{P_{\mathrm{o}}}$

where $\lambda$ is wavelength, $P$ is pressure, and $P_{\mathrm{o}}$ is standard pressure (Iqbal, 1983).

Since total extinction is composed of the sum of aerosol extinction and Rayleigh extinction, aerosol extinction is determined from the difference of the total extinction, as measured by the MFRSRs, and Rayleigh extinction. However, this calculation only provides aerosol extinctions at those wavelengths measured directly by the MFRSRs. A power law relationship is used to interpolate aerosol extinction throughout the spectrum of interest (Iqbal, 1983).

$\beta_{\mathrm{A}}=A \lambda^{\alpha}$

Measurements taken by the ASD spectroradiometer provide a direct measurement of surface radiances and surface reflectances. This instrument was calibrated by ASD in the spring of 1999. In addition, a Spectralon reflectance panel was used for onsite calibration during the campaign. Characterizations of the panel/spectroradiometer combination have indicated an accuracy of $2 \%$ (1 S.D.). Surface radiances at the time of the Landsat 5 overpass are shown in Fig. 5 . The average spectra from six passes of the test site are recorded in this figure. Although the satellite overpasses occurred close

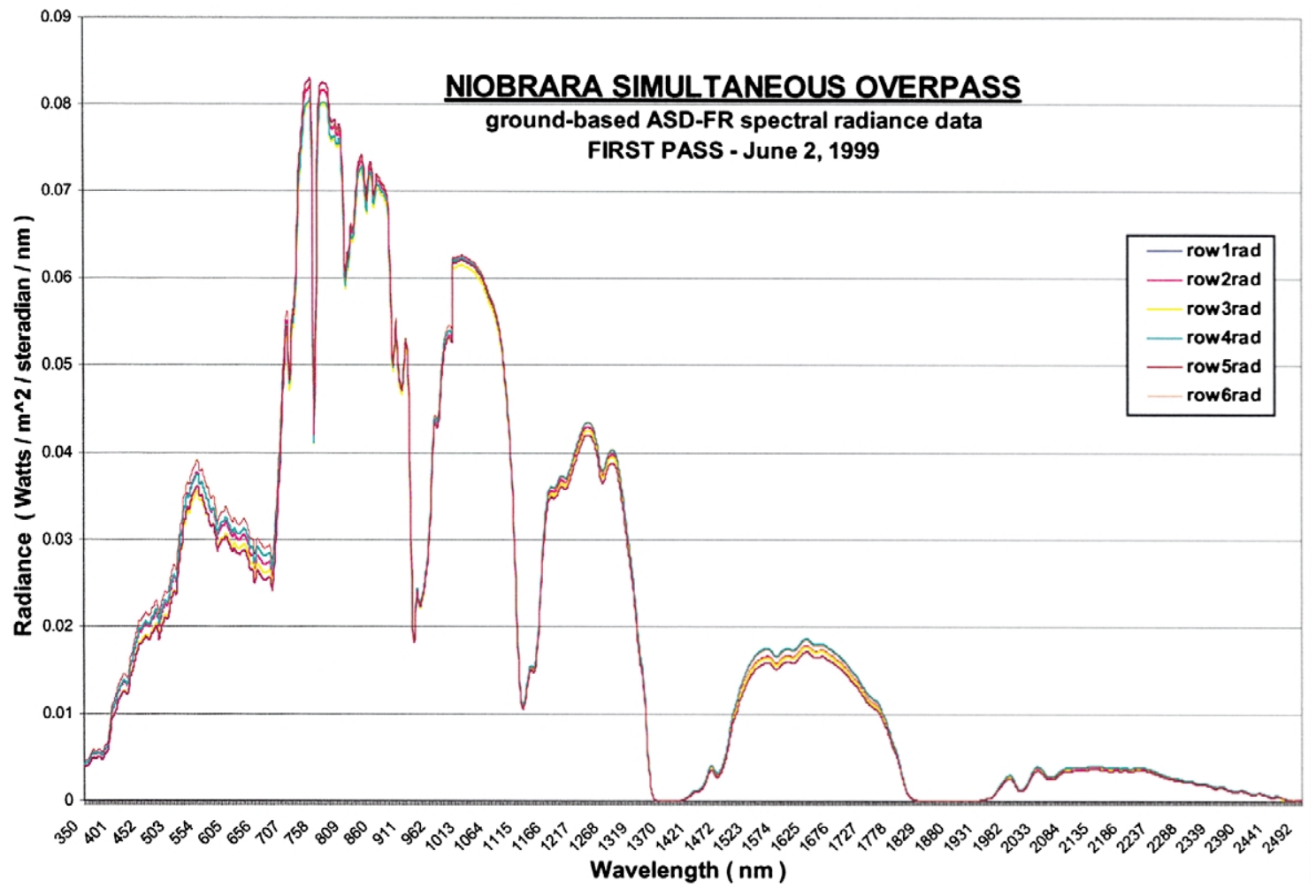

Fig. 5. Surface radiances of a vegetated target acquired at time of L5 overpass. 
to solar noon, it is evident that significant changes in surface radiances occurred during the $15 \mathrm{~min}$ needed to traverse the test site six times. The six curves shown in the figure are a direct measurement of the effect of sun angle and atmospheric change that occurred during the time period of the satellite overpasses. Worst case indicates a change in radiance on the order of $5 \%$ during the time period. In order to minimize this effect, we used 4-min averages, centered at overpass time, of MFRSR and spectroradiometer data were used for the atmospheric modeling step.

\section{Niobrara field campaign results}

Data collected during the field campaign were used as inputs to develop a radiative transfer model of the atmosphere. MODTRAN (PcModWIN3.7, Ontar, North Andover, MA) was used in its transmittance mode to model the transmittances recorded by the MFRSRs at overpass time. Inputs to the model included the derived aerosol and Rayleigh extinctions mentioned previously. Results for Landsat 7 (Table 4) indicate that agreement of the model with actual measurements is on the order of $1.5 \%$ or less for all channels except for Channel $5(1650 \mathrm{~nm})$, with a difference of $2.7 \%$. Results were similar for Landsat 5 , with a maximum difference in Channel 5 of $2.6 \%$. The MODTRAN model was also optimized in its radiance mode configuration by matching model diffuse-to-global ratio predictions with actual measured values (Table 5). Differences between model results and field measurements are somewhat larger for diffuse-to-global ratios. They range from a minimum of $4.0 \%$ in Channel $2(415 \mathrm{~nm})$ and a maximum of $8.0 \%$ in Channel $4(615 \mathrm{~nm})$. Landsat 5 results were similar with differences ranging from $2.2 \%$ in Channel $5(673 \mathrm{~nm})$ up to $10.2 \%$ in Channel $6(870 \mathrm{~nm})$. Model parameters that produced minimum differences in the transmittance mode did not necessarily produce minimum differences in the radiance mode. Surface reflectance inputs to the model were based on the Spectralon panel. Thus, the model was optimized for a set of parameters, produced on the basis of MFRSR and Spectralon panel calibration, that produced overall minimal differences in both modes simultaneously.

As an independent check on model accuracy, MODTRAN predictions of surface radiance were checked against

Table 4

Comparison of transmittances at different wavelengths between MFRSR measurements and MODTRAN simulations

\begin{tabular}{llll}
\hline Landsat 7 transmittance model & & \\
\hline Wavelength $(\mathrm{nm})$ & MFRSR & Modtran & Difference $(\%)$ \\
\hline 415 & 0.651 & 0.661 & 1.62 \\
500 & 0.782 & 0.792 & 1.25 \\
615 & 0.841 & 0.852 & 1.26 \\
673 & 0.876 & 0.900 & 2.71 \\
870 & 0.957 & 0.953 & 0.49 \\
\hline
\end{tabular}

MFRSR $=$ Multifilter Rotating Shadowband Radiometer
Table 5

Comparison of diffuse-to-global ratios at different wavelengths between MFRSR measurements and MODTRAN simulations

\begin{tabular}{llll}
\hline Landsat 7 diffuse-to-global model & & \\
\hline Wavelength $(\mathrm{nm})$ & MFRSR & Modtran & Difference (\%) \\
\hline 415 & 0.221 & 0.230 & 4.04 \\
500 & 0.128 & 0.135 & 5.82 \\
615 & 0.072 & 0.078 & 8.00 \\
673 & 0.058 & 0.062 & 6.12 \\
870 & 0.047 & 0.045 & 5.11 \\
\hline
\end{tabular}

actual surface radiance measured independently by the FieldSpec FR. Surface reflectance measurements used in the MODTRAN modeling were based on the calibration of a Spectralon reflectance panel. Fig. 6 shows the results as percentage error for both the Landsats 5 and 7 models with respect to the measured upwelling radiance from the surface. If these are integrated over the bandwidth of the two instruments, the average errors for Bands $1-5$ of Landsat 5 are $7.6 \%, 8.4 \%, 5.2 \%, 4.3 \%$, and $5.4 \%$, respectively. For Landsat 7, the corresponding errors for Bands 1-5 are $5.8 \%, 6.0 \%, 2.9 \%, 5.8 \%$, and $3.1 \%$, respectively. After this check was done, the model was used to predict the top of the atmosphere radiance as measured by the satellite sensors.

In order to calculate instrument gain, the pixels corresponding to the test site needed to be located in the Landsat imagery, corrections made for instrument artifacts, detector bias removed, and relative detector gains compensated for. Location of the pixels is greatly simplified through use of the blue tarps (Fig. 4). To avoid any effects caused by the instrument point-spread function, we did not use pixels immediately adjacent to the tarps nor pixels located near the edge of the test site. As a result, a $5 \times 4$-pixel area was chosen. In addition to this, in order to ensure that the atmospheric point-spread function was not causing any adjacency effects, we analyzed histograms of the test site pixels and the surrounding pixels. In all Landsat bands, the mean of the pixel values of the test site region was essentially equal to the mean of the pixel values of the surrounding region. Standard deviations of the histograms of the test site were slightly less than standard deviations of histograms of the surrounding region. This indicated that there was essentially no significant difference in brightness between test site pixels and surrounding pixels. Therefore, atmospheric adjacency effects are minimal and can essentially be ignored in this analysis.

Fortunately, for Landsat 7, no artifact correction was necessary. However, for Landsat 5, corrections for ME were made. SCS is automatically accounted for when detector bias is removed on an individual scan basis using bias information recorded in the calibration file. No corrections were made for $\mathrm{CN}$. Lastly, in order to obtain an overall band-averaged gain, differences in individual detector gain need to be accounted for. In the case of Landsat 5, relative detector gains were obtained by analyzing a stable site, Railroad Valley, NV, over the lifetime of the instrument 


\section{ModTran Model Matching}

comparison of

modOut2 (L5r5.Itn \& L7r5.ltn) with Niobrara ASD-FR (06/02/99)

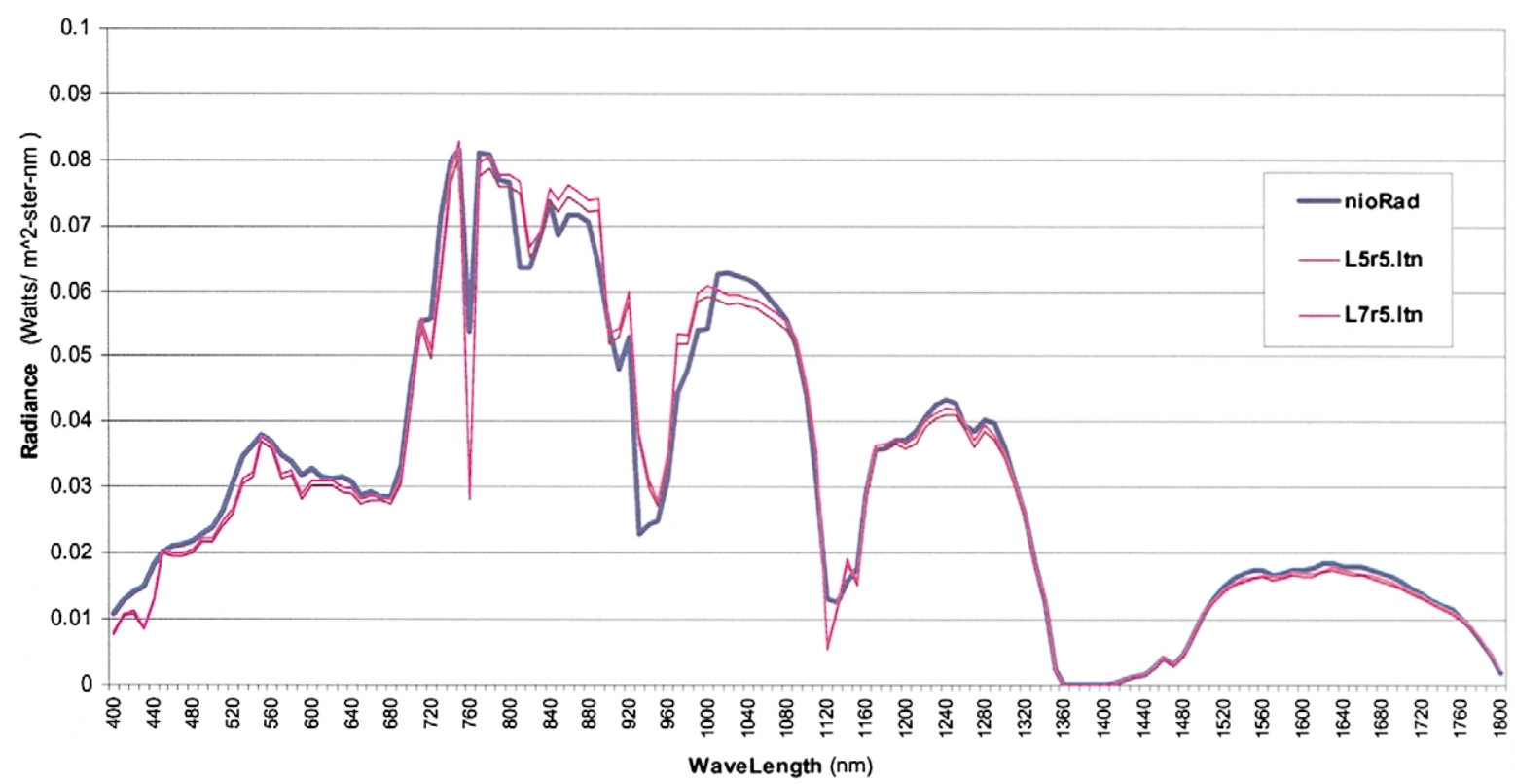

Fig. 6. Percentage of error between MODTRAN models and measured surface radiance.

(Benson, 2001). These results indicated that the relative gains of the detectors have been very stable and have been characterized over the entire instrument life with an error of significantly less than $1 \%$. For Landsat 7 , such an extensive study is not available. However, prelaunch evaluations of detector gains are available, and initial postlaunch analyses have also been performed (B. Markham, personal communication). Once individual detector responses have been determined, then all 20 resulting pixels values in the test site area can be averaged for estimation of band-average gain. It should be noted that owing to the size of the test site only five detectors in each band were actually used. However, comparisons of these detectors with all 16 detectors in the band indicated that they were very representative of the entire band. Differences in mean value of relative detector gain between the detector subset used in this study and all detectors in the band were significantly less than $1 \%$.

Table 6

Landsat $5 \mathrm{TM}$ and Landsat $7 \mathrm{ETM}+$ band average gains as derived from the Niobrara field campaign

\begin{tabular}{lcc}
\hline Band averaged gains $\left(\mathrm{DN} / \mathrm{W} \cdot \mathrm{m}^{-2} \cdot \mathrm{sr}^{-1} \cdot \mu \mathrm{m}^{-1}\right)$ \\
\hline Band & Landsat 5 & Landsat 7 \\
\hline 1 & 1.221 & 1.244 \\
2 & 0.662 & 1.201 \\
3 & 0.904 & 1.570 \\
4 & 0.980 & 1.378 \\
5 & 7.681 & 7.323 \\
7 & 16.91 & 23.34 \\
\hline
\end{tabular}

Band average gains for Landsats 5 and 7 are shown in Table 6 . These were calculated by dividing the resulting DN values obtained from the preceding analysis by the top of the atmosphere radiance predicted by the radiative transfer code. At the time of overpass, all reflective bands for Landsat 7 were set to high gain. Errors on these estimates are approximately $7 \%$.

It is illustrative to compare these results with those previously obtained for Landsat 5 . Fig. 1 shows the estimated gain of the Landsat 5 reflective bands over the lifetime of the instrument. Vicarious calibrations performed by the University of Arizona's Remote Sensing Group are shown by the "triangle" symbol. The calibrations reported in this study are shown with a "square" at the right end of each graph. Also shown on the plots are solid lines representing the calibration of the instrument as determined by the IC. These curves have been normalized to the 1988 University of Arizona cal-

Table 7

Comparison between Landsat 7 ETM+ prelaunch and Niobrara-derived band averaged gains

\begin{tabular}{lccc}
\hline \multicolumn{4}{l}{ Landsat 7 band averaged gains $\left(\mathrm{DN} / \mathrm{W} \cdot \mathrm{m}^{-2} \cdot \mathrm{sr}^{-1} \cdot \mu \mathrm{m}^{-1}\right)$} \\
\hline Band & Prelaunch & Niobrara & Difference (\%) \\
\hline 1 & 1.211 & 1.244 & +2.7 \\
2 & 1.161 & 1.201 & +3.4 \\
3 & 1.519 & 1.570 & +3.4 \\
4 & 1.533 & 1.378 & -10.1 \\
5 & 7.601 & 7.323 & -3.7 \\
7 & 22.55 & 23.34 & -3.5 \\
\hline
\end{tabular}


Table 8

Empirically derived slope and intercept values enabling radiometric conversion of Landsat $7 \mathrm{ETM}+\mathrm{DN}$ values to Landsat $5 \mathrm{TM}$ DN values

\begin{tabular}{llll}
\hline Band & Slope & Intercept & $R^{2}$ \\
\hline 1 & 1.060 & -4.21 & .9960 \\
2 & 0.563 & -2.58 & .9977 \\
3 & 0.650 & -2.50 & .9981 \\
4 & 0.701 & -4.80 & .9981 \\
5 & 1.016 & -6.96 & .9983 \\
7 & 0.767 & -5.76 & .9980 \\
\hline
\end{tabular}

Relationships were based upon comparisons between Landsats 5 and 7 near-simultaneous data acquisitions on June 2, 1999 at Niobrara, Nebraska. Landsat 7 gain levels were high for all bands used.

ibration point. All data are shown with 1 S.D. error bars. From the plots, it is apparent that the IC-based calibration and the vicarious calibration trend very well until about 1988. At this time, the IC calibrations tend to show a general increase in gain over time while the vicarious calibrations show either a steady or decreasing gain that is band dependent. Also, there is excellent agreement between the Arizona vicarious calibrations and the calibration reported here in Bands 1-3. Bands 4, 5, and 7 show somewhat larger differences.

These observations tend to suggest that the IC was tracking the instrument gain well until about 1988. After that time, the performance of the IC tends to diverge from the vicarious calibrations. Since the vicarious calibrations have been performed independently, by two different teams, this divergence suggests the IC response has somehow degraded since 1988 and probably should be renormalized to the vicarious calibrations and used as an interpolator for those dates when vicarious information is not available.

Landsat 7 has no lengthy history of calibrations for comparison. However, comparisons can be made to prelaunch measurements of instrument gain (Table 7). There is very good agreement, on the order of $3.5 \%$, for all reflective bands except Band 4 , which shows a $10 \%$ difference. These results suggest that the instrument survived launch with little shift in the gains of the reflective bands. Further results from the full aperture calibrator, partial aperture calibrator, and other vicarious calibrations will help substantiate these

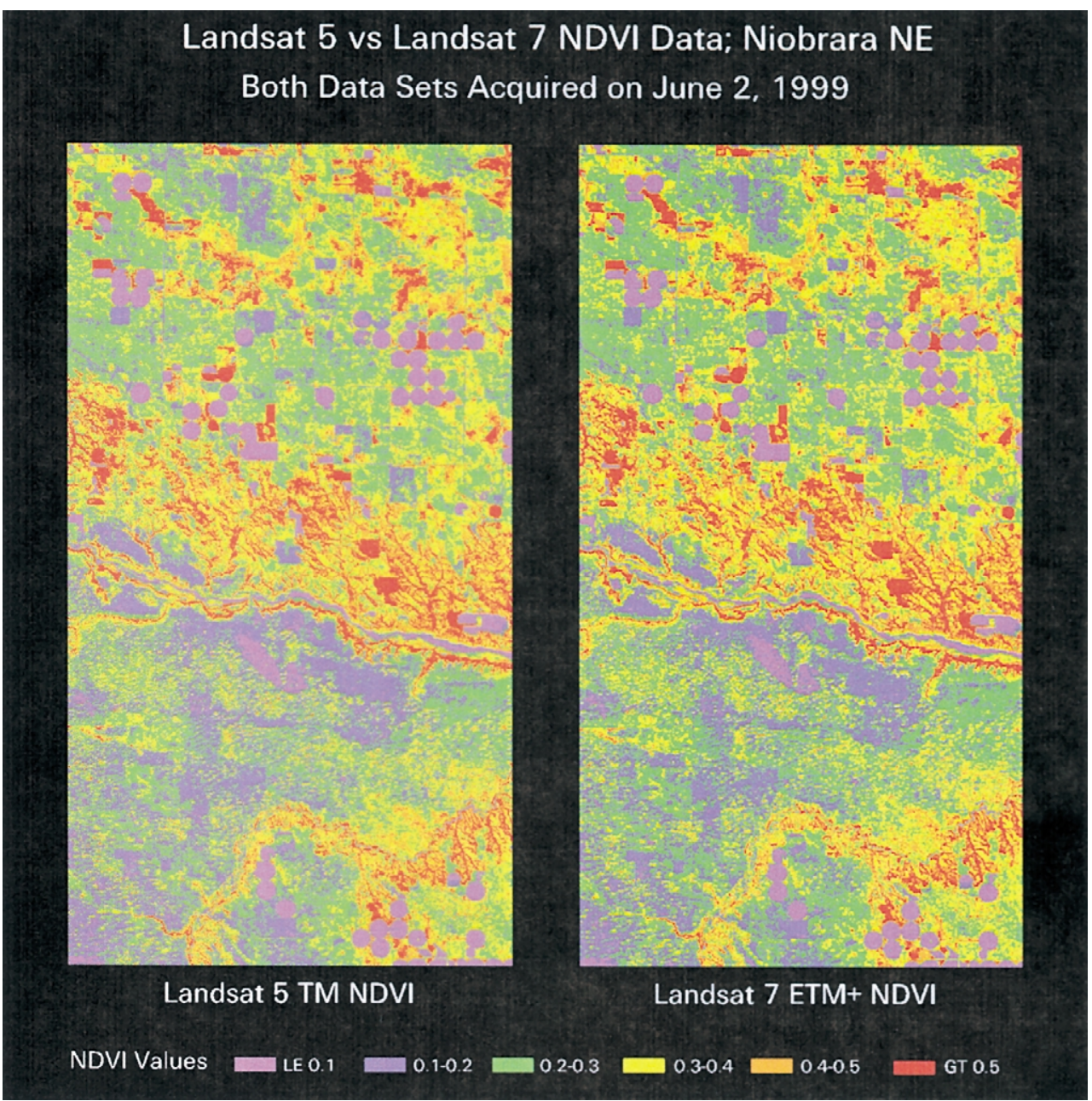

Fig. 7. Comparison between NDVI images acquired on June 2, 1999 from Landsats 5 and 7. 
initial findings and establish any trends in calibration over time, such as those exhibited by Landsat 5 .

\section{Landsat 5 TM and Landsat 7 ETM+ image comparisons; Niobrara}

To compare the June 2 Landsat 5 TM and June 2 Landsat 7 ETM+ data from the Niobrara site, we selected 21 large, homogeneous targets and extracted mean DN values from both data sets for Bands 1-5 and 7. Sites that were used included water bodies, agricultural fields (both vegetated and nonvegetated), bare areas, native prairie sites, and conifer forests. Because of the short time interval between the two data acquisitions (approximately $13 \mathrm{~min}$ ), it was assumed that these areas did not undergo spectral or radiometric change over the time period. Mean DN of Landsat 5 vs. Landsat 7 data were plotted against each other for each band, and radiometric regression (Schott, Salvaggio, \& Volvhok, 1988) equations were used to convert DN values from Landsat 7 band values (excluding the pan and thermal bands) to Landsat 5 TM units (Table 8). Band-to-band relationships between the two data sets were very high for all bands, with $r^{2}$ values $(n=21)$ ranging from .9912 (Band 1) to .9996 (Band 4). For this part of the investigation, no special radiometric corrections were applied to either data sets except for the radiometric rectification procedure for the Landsat 7 data. Landsat 7 data were processed through the Image Assessment System (IAS), and the Landsat 5 data were processed through the National Landsat Archive Production System (NLAPS). Images were registered by means of image-to-image registration using nearest neighbor resampling (root mean square value of less than 1 pixel).

NDVI images were produced from "raw" DN values from Landsat 5 imagery and the radiometrically and geometrically referenced Landsat 7 imagery. Specific ranges of NDVI were then coded specific colors (Fig. 7). Results from this part of the investigation indicate that the NDVI data sets from Landsats 5 and 7 are very comparable following radiometric normalization. Although there are a few instances in which some differences between the NDVI images can be noted (especially along spectral edges), for the most part the data match very well. A random sample of 1000 pixels was selected, and NDVI values from both Landsats 5

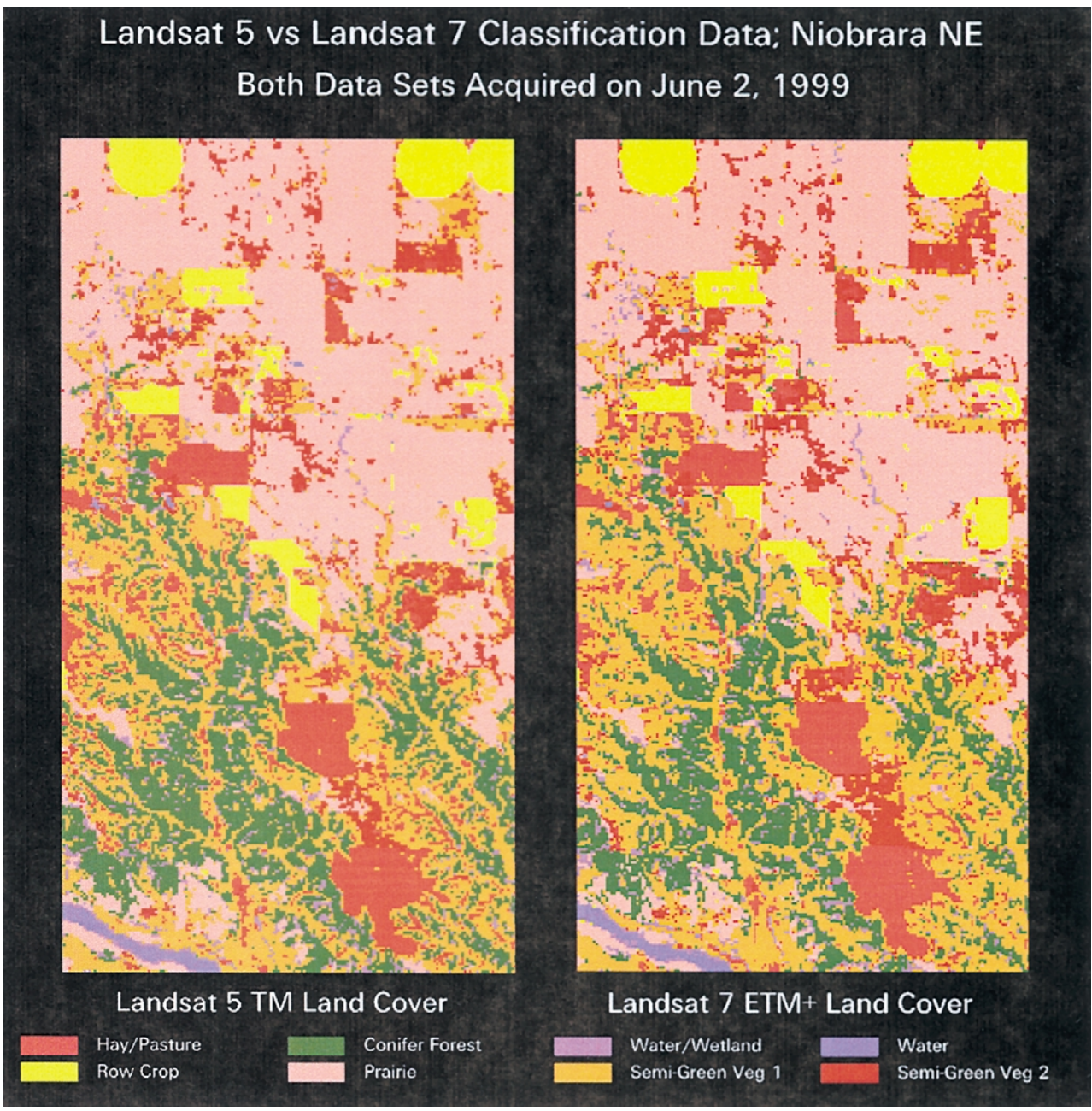

Fig. 8. Comparison between classification images acquired on June 2, 1999 from Landsats 5 and 7. 
and 7 data sets were extracted and linearly regressed against each other. The $r^{2}$ value for the relationship was .953 , which indicates high agreement between the two data sets, especially when considering that much of the disagreement undoubtedly resulted from imperfect georegistration of data sets. The linear regression equation from these points essentially indicated a one-to-one relationship. In addition, individual Landsat 7 bands were found to be very comparable to analogous Landsat 5 bands. This bodes well for the issue of Landsat data continuity and the ability to consistently characterize the landscape through time.

Maximum likelihood classification images were also produced from "raw" DN values from Landsat 5 imagery and the radiometrically and geometrically referenced Landsat 7 imagery. Statistics from 20 training areas representing the dominant types of land cover were used to classify the data, and the resulting spectral classes were recoded to eight land cover classes for both Landsats 5 and 7 classification data sets (Fig. 8). As noted for the NDVI comparisons, classification data sets from Landsat 7 and Landsat 5 are very comparable. Although there are a few instances in which some differences between the classification images can be noted, for the most part, the classification data sets are statistically (Table 9) and visually (Fig. 8) similar. In addition, landscape metrics (LPI, LSI, and CONTAG) were calculated from the classification products. As expected, results were very similar between Landsats 5 and 7 classifications.

Statistical analyses of DN properties were also conducted to further describe the data quality of Landsats 5 and 7 sensors. Landsat 7 ETM+ data were compared with Landsat 5 data that were corrected for instrument artifacts (ME, gain/bias, interfocal plane offsets). Coefficient of variation $(\mathrm{CV}$; standard deviation divided by mean) values were derived for each band from each of the 21 targets used for radiometric rectification and averaged (Table 10). The values were found to be statistically lower for Landsat 7 $\mathrm{ETM}+$ than for Landsat $5 \mathrm{TM}$ data for five of six bands (0.05 level of confidence or better; Table 9). The targets used for this investigation were assumed to be spectrally homogeneous, and it was assumed that $\mathrm{CV}$ values would

Table 9

Land cover class area estimates derived from near-simultaneous Landsats 5 and 7 data acquisitions

\begin{tabular}{lcc}
\hline Land cover class & $\begin{array}{l}\text { Landsat 5 } \\
\text { classification }\end{array}$ & $\begin{array}{l}\text { Landsat 7 } \\
\text { classification }\end{array}$ \\
\hline Hay/pasture & 103.7 & 91.4 \\
Row crop & 117.5 & 120.5 \\
Conifer forest & 78.2 & 65.5 \\
Prairie & 976.8 & 950.9 \\
Wetland & 66.5 & 78.7 \\
Water & 7.8 & 7.1 \\
Semigreen vegetation (A) & 330.9 & 318.3 \\
Semigreen vegetation (B) & 141.1 & 189.9 \\
\hline
\end{tabular}

Estimates are in square kilometers. Total area classified was approximately $1823 \mathrm{~km}^{2}$
Table 10

Comparison between Landsats 5 and 7 ETM+ mean CV values from 21 targets at Niobrara, NE

\begin{tabular}{lllc}
\hline Band & Mean CV (Landsat 5) & Mean CV (Landsat 7) & $P$ value \\
\hline 1 & 0.0256 & 0.0228 & .0263 \\
2 & 0.0356 & 0.0292 & .0071 \\
3 & 0.0485 & 0.0506 & .4096 \\
4 & 0.0542 & 0.0415 & .0494 \\
5 & 0.0587 & 0.0368 & .0067 \\
7 & 0.0895 & 0.0499 & .0017 \\
\hline
\end{tabular}

$P$ value indicates probability that Landsats 5 and $7 \mathrm{CV}$ values are different on the basis of one-tailed Student's $t$ test.

Landsat 5 values are based on data sets in which radiometric and geometric artifacts were removed.

serve as estimates of instrument noise (i.e., the lower the $\mathrm{CV}$ values, the less the instrument noise). Thus, this analysis provides evidence that Landsat $7 \mathrm{ETM}+$ noise levels are lower than those for current Landsat $5 \mathrm{TM}$ data.

\section{Landsat 7 ETM+ difference data}

After a procedure was used to radiometrically rectify the Landsat 7 July 28 Niobrara scene with the Landsat 7 July 12 Niobrara scene, and image-to-image geometric rectification was done, difference images were produced. No effort was made to remove potential instrument-related radiometric artifacts. Images produced were of very good quality, with no striping patterns or other artifacts being manifest in the data. This was true for the pan band as well. Although these are admittedly qualitative assessments, similar products using uncorrected Landsat 5 data invariably show obvious patterns of noise due to instrument-related artifacts. From an applications standpoint, the absence of these artifact-related patterns in the Landsat 7 difference images indicates an obvious improvement of Landsat 7 data over Landsat 5 data.

\section{Conclusions}

Results from this investigation have provided information on the relative effects of radiometric and geometric artifacts on Landsat 5 image products. Although some applications are relatively robust and not heavily affected by the calibration and correction procedures used, others appear to be much more sensitive. Landsat 7 ETM + data are devoid of many of the instrument-related artifacts that characterize Landsat 5 TM data. Nonetheless, image products from June 2, 1999, Landsats 5 and 7 data indicate a high degree of similarity, which implies that monitoring activities initiated using Landsat 5 data can be continued with a minimal amount of caution using Landsat 7 data. Results from the vicarious calibration activities indicate that Landsat 5 data deviate from IC data for some bands, especially post-1990. For the most part, field spectral data agree well with Landsat 7 prelaunch measure- 
ments. Future vicarious calibrations will be necessary to establish any trends in calibration over time, such as those shown by Landsat 5 .

\section{Acknowledgments}

This work was performed in part by Raytheon under US Geological Survey Contract 1434-CR-97-CN-40274 and NASA grant S-41395-F. Participation by the University of Nebraska was funded by NASA grant NAG 5-3442.

\section{References}

Barker, J. L. (1983). Landsat 4 sensor performance. In: Proceedings of Pecora VIII Symposium, Satellite Land Remote Sensing Advancements for the Eighties, Sioux Falls, South Dakota, October 4-7, 46-74.

Barker, J. L., \& Seiferth, J. C. (1996). Landsat Thematic Mapper band-toband registration. In: Proceedings of the IGARSS'96 Symposium: Remote Sensing for a Sustainable Future, Lincoln, Nebraska (pp. 1600-1602).

Benson, K. (2001). Unpublished data from research conducted at EROS Data Center. Piscataway, NJ: Institute of Electrical \& Electronic Engineering, Inc.

Berk, A., Bernstein, L. S., \& Robertson, D. C. (1989). MODTRAN: a moderate resolution model for LOWTRAN 7. Technical Report PLTR-89-0122. US Air Force Phillips Laboratory, Hanscon Air Force Base, Massachusetts.

Brest, C. L., \& Rossow, W. B. (1992). Radiometric calibration and monitoring of NOAA AVHRR data for ISCCP. International Journal of Remote Sensing, 13, 235-273.

Forman, R. T. T., \& Godron, M. (1986). Landscape ecology. New York: Wiley.

Frohn, R. C. (1998). Remote sensing for landscape ecology: new metrics for monitoring, modeling, and assessment of ecosystems. New York: Lewis Publishers.

Gutman, G. G. (1999). On the monitoring of land surface temperatures with the NOAA/AVHRR: removing the effect of satellite orbit drift. International Journal of Remote Sensing, 20, 3407-3413.

Helder, D. (1996). A radiometric calibration archive for Landsat TM. In: Proceedings of SPIE: Algorithms for Multispectral and Hyperspectral Imagery, Orlando, FL, April 9, 1996. SPIE 2758, 273-284. Bellingham, WA: The international society for optical Engineering.

Helder, D. (1999). Radiometric characterization and calibration of Landsat 4/5 Thematic Mappers. Available at http://iplab2out.sdstate.edu/tmcal. Piscataway, NJ: Institute of Electronical \& Electronic Engineers, Inc.

Helder, D., Barker, J., Boncyk, W., \& Markham, B. (1996). Short term calibration of Landsat TM: recent findings and suggested techniques. In: Proceedings of the IGARSS'96 Symposium: Remote Sensing for a Sustainable Future, Lincoln, Nebraska (pp. 1286-1289).

Helder, D., Boncyk, W., \& Morfitt, R. (1997). Landsat TM memory effect characterization and correction. Canadian Journal of Remote Sensing, 23, 299-308.

Helder, D., Boncyk, W., \& Morfitt, R. (1998). Absolute calibration of the Landsat Thematic Mapper using the internal calibrator. In: International Geoscience and Remote Sensing Symposium, Seattle, WA, July 6-10.

Iqbal, M. (1983). An introduction to solar radiation (390 pp.). New York: Academic Press.

Kaufman, Y. (1989). The atmospheric effect on remote sensing and its correction. In: G. Asrar (Ed.), Theory and applications of optical remote sensing (pp. 336-428). New York: Wiley.

McGarigal, K., \& Marks, B. J. (1993). FRAGSTATS: spatial pattern analysis program for quantifying landscape structure. In: FRAGSTATS software manual (65 pp.). Corvallis: Oregon State University.

NASA (1985). Characterization of Landsat 5 Thematic Mapper reflectance bands. NASA, Goddard Space Flight Center (internal document prepared by R. B. Abrams).

Pan, D., Domon, G., de Blois, S., \& Bouchard, A. (1999). Temporal $(1958-1993)$ and spatial patterns of land use changes in Haut-SaintLaurent (Quebec, Canada) and their relation to landscape physical attributes. Landscape Ecology, 14, 35-52.

Privette, J. L., Fowler, C., Wick, G. A., Baldwin, D., \& Emery, W. J. (1995). Effects of orbital drift on advanced very high resolution radiometer products: normalized difference vegetation index and sea surface temperature. Remote Sensing of Environment, 53, 164-171.

Riitters, K. H., O’Neil, R. V., Hunsaker, C. T., Wickman, J. D., Yankee, D. H., Timmins, S. P., Jones, K. B., \& Jackson, B. L. (1995). A factor analysis of landscape pattern and structure metrics. Landscape Ecology, $10,23-39$.

Schott, J. R., Salvaggio, C., \& Volchok, W. J. (1988). Radiometric scene normalization using pseudoinvariant features. Remote Sensing of Environment, 26, 1-16.

Teillet, P. M., Slater, P. N., Ding, Y., Santer, R. P., Jackson, R. D., \& Moran, M. S. (1990). Three methods for the absolute calibration of the NOAA AVHRR sensors in-flight. Remote Sensing of Environment, $31,105-120$.

Vogelmann, J. E., Choate, M. J., Helder, D., Merchant, J. W., \& Bulley, H. (1999). Effects of Landsat Thematic Mapper radiometric and geometric calibrations on selected land cover analyses. In: Proceedings of the Pecora 14/Land Satellite Information III Conference, December 610, Denver, CO (CD ROM). Bethesda, MD: American Society for Phologrammetry and Remote Sensing.

Vogelmann, J. E., Helder, D., Morfitt, R., Choate, M. J., \& Merchant, J. W. (1998). Characterization of Landsat Thematic Mapper radiometry for land cover analyses. In: Proceedings of the IGARSS'98 Symposium, July 6-10, Seattle, WA (CD ROM). Piscataway NJ: Institute of Electrical and Electronic Engineers Inc. 